\title{
ACADEMICS' CONCEPTIONS OF HIGHER EDUCATION DECOLONISATION
}

\author{
J. Sibanda \\ School of Education \\ Sol Plaatje University \\ Kimberley, South Africa \\ e-mail: Jabulani.Sibanda@spu.ac.za / https://orcid.org/0000-0001-6788-470X
}

\section{ABSTRACT}

The urgency for a decolonised university curriculum in South Africa, occasioned by student protests, demands interrogation of conceptions of decolonisation academic staff hold, seeing that the design and implementation of decolonised education rests largely with them. To determine the academics' conceptions, the study adopted the interpretivist paradigm, using semi-structured interviews to solicit data from 13 purposively sampled academic staff at a South African university. Data analysis took a grounded analysis approach, where content analysed categories/themes emerged from the transcribed and coded data, not from apriori assumptions. Findings reflected both the conception of decolonisation as recentring and decentring. Findings also pointed to the ubiquitous use of the terms Africa and African(s) in defining decolonisation, conflating Afrocentric philosophy and Africanisation with decolonisation. Such findings represented the conception of decolonisation as a recentring of curriculum from the West to Africa as the centre. Other academics' conceptions also represented a decentring of knowledge from Western hegemony without necessarily recentring it to African hegemony. Much advocacy was for achieving equality and parity between extant knowledges and hitherto marginalised local knowledges. There was also a manifest vacillation in respondents' conception of decolonisation as they responded to the different questions, almost evincing a continuum between what can be termed a hard version and a soft version of the concept. The study recommends broader, intensive, institutional discussion of conceptual issues around curriculum decolonisation prior to implementation.

Keywords: Africanisation, decolonisation, indigenisation, knowledges, transformation

\section{INTRODUCTION}

The university allegedly operates within and along, post-colonial, global, and Western cultural traditions, thought and epistemological practices, alien to the black and African experience. Universities have long and unapologetically sought to pattern themselves after the likes of Harvard and Oxford, rendering them complicit in promulgating Western cosmovisions through "reproduction of epistemological blindness that silences other knowledges and ways of creating knowledge" (Motta 2013, 97). The African student has to ignore their own practices and knowledge frames, and adopt Western ones to realise success in these allegedly highly 
Westernised institutions, hence; the call for decolonisation.

The decolonisation call is not a novel one. Nkwame Nkrumah longed for universities planted in the African soil to take root amidst African traditions (Le Grange 2014). The call for decolonisation is occasioned by, among other things, the perceived stagnation of curriculum when the profile of the Higher Education (HE) student cohort it is meant to serve, has shifted radically, courtesy of the widening physical access to higher education. The typical young, white, middle class student geared for university education does not reflect the generality of the extant student profile in the African context, rendering the university obsolete. Alignment of curriculum to student demographics engenders success. However, Kasturi $(2019,58)$ observes how post-1994 South African HE has prioritised demographic and structural changes at the expense of addressing "... low throughput rates for black students". The decolonisation discourse seeks to ensure the link between epistemological and ontological access; where access to knowledge (epistemological access) is a function of the congruence of that knowledge with the nature of being of the recipients (their ontology). This explains the myriad calls for decolonisation.

The decolonisation hype has rendered "decolonisation" a buzzword at conferences, workshops, epistemic debates, and in student protests over the years. Despite its ubiquitous use, decolonisation and related concepts are "contested, have different meanings in different discourses, and do not have fixity ..." (Le Grange 2018, 8). Although a precise singular definition of decolonisation is, in my view, neither possible nor desirable; academics' conception of the nuanced nature of decolonisation merits scrutiny, considering that they are arguably, the single most important stakeholder in curriculum design, development, implementation and evaluation. Clarity of conception on their part would ensure they do not implement one thing in the name of the other.

In determining academics' decolonisation conceptions, it is imperative to acknowledge decolonisation as largely and essentially a knowledge and power project, meant to redress power differentials in the determination of what is knowledge, its creation, dissemination and evaluation. Le Grange $(2018,8)$ posits that in HE “... the systems of power that classify (also known as othering), denigrate, and subjugate remain prevalent, and, in a contemporary globalising world, are more insidious than previous more naked forms of colonisation were". My crystallisation and synthesis of reviewed literature yields four decolonisation advocacy points or perspectives (based on knowledge and power) which, I posit, encapsulate the diversity of decolonisation conceptions.

\section{LITERATURE REVIEW}

The four perspectives to decolonisation, gleaned from literature, which framed the study are; 
decolonisation as recentring, decolonisation as de-centring, decolonisation as unboxing knowledge, and decolonisation as facilitation of access to powerful knowledges. Before presenting the four perspectives, it is imperative to identify what they are premised upon. They are premised on the hegemony of the Global North in determining knowledge, its production and beneficiaries. Chiumbu (2017) opines that coloniality of knowledge occurs where Western or Eurocentric knowledge is so privileged and dominant over other epistemes to the extent that it becomes common sense, normal, ideal, universal and hegemonic. She observes that the legitimated knowledge is then pedalled as supposedly neutral and universal, and any other knowledge as, not only pedestrian, but also "provincial and situated." Her question, "[w]hy has Eurocentered epistemology carefully hidden its own geo-historical and bio-graphical locations?" (2017, 3) accuses Western episteme of masquerading as global or universal knowledge. The net effect is that peripheral knowledges remain at the margins ever trying to "become" without really "being". Emeagwali and Sefa Dei (2014) observe how Western systems of knowing discredit alternative, multiple, collaborative, and accumulative knowledge dimensions as mythical, superstitious, primitive, culture-based, static, non-scientific, and unworthy of scholarly engagement within the university system.

According to Mbembe $(2015,10)$, “... hegemonic tradition ... actively represses anything that actually is articulated, thought and envisioned from outside of these frames". Hegemony is manifest where the globalisation of knowledge is nothing more than "... a systematic process through which the West reaffirms its power as a centre of legitimate knowledge" (Chilisa et al. 2016, 314). Hegemony relegates some knowledges to oblivion while others are given mileage, immutability and sole legitimacy. Within this intricate politics of knowledge, decolonisation perspectives tend to problematise the locus of enunciation. The knowledge systems framework is instructive to a view of knowledge as outcome and as process, which consequentially affects the scope of decolonisation. Having established the coloniality of knowledge and its attendant power dynamics, I discuss the four perspectives in turn.

\section{Decolonisation as recentring}

For Kasturi $(2019,59)$, decolonisation “... calls for a re-positioning and recentring of that which is sacred and indigenous and home-grown". Le Grange (2016) sees recentring as, not only bringing peripheral and marginalised knowledges into the mainstream, but also making them central. It represents a reversal of hegemony between legitimated and marginalised ways of knowing. For Mbembe (2015), decolonisation “... is not about closing the door to European or other traditions. It is about defining clearly what the centre is". Similarly, Chiumbu $(2017,4)$ notes that “... it's not ignoring Western knowledge, but it is about re-centring Africa and its 
experiences". The authors advocate retention of a "centre" and changing that centre. In eschewing epistemic universalism, Africanisation considers, as a point of departure, African subjectivity. Ngũgĩ wa Thiong'o (1986), cited in Kasturi (2019, 66), also believes decolonisation "... is about defining clearly what the centre is and mapping out the directions and perspectives that studies should take if Africa is placed at the centre". In short, this perspective shifts the centre from the privileged to the marginalised knowledge.

\section{Decolonisation as decentring}

Le Grange (2016) observes that decentring is actuated by a desire to obliterate the hegemonic sway of Western knowledges to ensure parity and equality of knowledges. Olivier (2019) reckons that epistemic justice stems from epistemic autonomy which, itself, is a measure of the appropriation of diverse knowledges into the academy, including the hitherto "unacknowledged and/or suppressed". The obsession to rid "... all vestiges of erstwhile colonial powers from university curricula" is regarded narrow and parochial (Olivier 2019) and a plurality of ways of knowing, with each knowledge defining the limits and possibilities of understanding other knowledges in an ecology of knowledges (Santos 2009), is advocated.

Within the decentring perspective, the decolonisation agenda desists from the totalitarianism of Western hegemonic epistemologies. For Ndlovu-Gatsheni (2013), this perspective calls for the democratisation of knowledge, de-hegemonisation of knowledge, deWesternisation of knowledge, and de-Europeanisation of knowledge. All internalized and naturalized frames of references are disrupted (Kasturi 2019,62) until there is no specific centre of enunciation.

\section{Decolonisation as unboxing knowledge}

In his review of the book Africanising the Curriculum: Indigenous Perspectives and Theories by Vuyisile Msila and Mishack T. Gumbo, Samuel (2017) posits that Western knowledges are not themselves of Western origin, but are merely a re-packaging and re-presentation of "[k]nowledges that crisscross the globe originating from one source of world" giving a semblance of them originating from the West. The notion of the West as the progenitor of all the privileged knowledge(s) in the academy is regarded as a myth. The West has just claimed, with impunity, the role of legitimating knowledge(s) that ascends the citadel of privilege and those that remain at the periphery, or get obliterated. It decides what voices to muzzle and what voices to trumpet. What this implies is that the dualism and dichotomisation or reduction and essentialisation of Western versus Indigenous knowledge is flawed.

In a veiled challenge to the labelling of knowledges, Samuel $(2017,89)$ posits that "[w]e 
are diverse, multiple, and continually contested beings, as new internal and external dialogues about who we are and who we want to be, consciously invade our being. Any attempt to box us is resisted." Boxing knowledges would render in-breeding knowledges coloured by habits, routines, and rituals, undesirable in the face of the porosity of boarders that occasion fluidity as well as physical, methodological, and epistemological migration. Within this perspective, knowledge is found at the intersection of the "emic and home grown culture specific" (Samuel $2017,90)$ and the etic, "generic, universalist" perspectives of the world we inhabit. The competition of ideas precludes exclusivity and celebrates dialectical exchange and contestation among diverse epistemic traditions, and the resultant plurality of ideas. Internationalisation and globalisation would not camouflage Western hegemony and there would not be any pyramids of knowledge.

\section{Facilitating access to powerful knowledges}

A decolonisation perspective which is not much prevalent in literature is represented by Leibowitz (2017) who sees decolonisation as essentially according to students' equal access to "most powerful forms of knowledge" using the most reliable methods that guarantee that access. The view acknowledges extant knowledges as powerful knowledges (implying less powerful and powerless knowledges). The restriction of access to the powerful knowledges is what needs redress through requisite pedagogies. Such a perspective does not seek to disrupt the extant knowledge systems, but their packaging and presentation.

Within these decolonisation perspectives, diverse conceptions of decolonisation should find resonance. It is within this framing of the knowledge project that academics' conception of decolonisation was solicited, as discussed in the methodology.

\section{METHODOLOGY}

This section discusses the methodological decisions that were made to collect the data for the study as well as to present and make sense of the data.

\section{Research paradigm}

The study used the interpretivist paradigm, which focuses on understanding and accounting for the meaning of participants' perceptions, experiences and actions. Cohen, Manion and Morrison (2011) see knowledge construction as being occasioned by descriptions of meanings of self-understanding. Participants in the study provided their own conceptions of decolonisation of the curriculum and how they envisage it would look like in their subject/ disciplinary specialisations. 


\section{Sampling}

The study had, as its population, all the 41 academic staff members in the School of Education at a South African University. Purposive sampling was employed to select academic staff. The following criteria were used to determine the sample: status (early career, emerging and established academics as determined by their qualifications, designations and university teaching experience), gender, racial group, and teaching specialisation. The purposive sampling procedure yielded a sample of 14 participants. Proportionate to the status demographic of the School, there were nine early career participants labelled A1 to A9, two emerging researchers labelled B1 and B2, and three established researchers labelled $\mathrm{C} 1$ to $\mathrm{C} 3$. The other criteria demographics were also represented proportionate to the population.

\section{Instrument}

Semi-structured interviews, which allowed for free-flowing directed discussion, were used. The semi-structured interview allowed for probing of responses given to the six interview questions which were asked. The data is presented according to the six questions that were posed to the respondents. The purpose was to generate a diverse range of views on few key questions to better understand conceptions held by academics. The interviews were audio-recorded with the participants' consent.

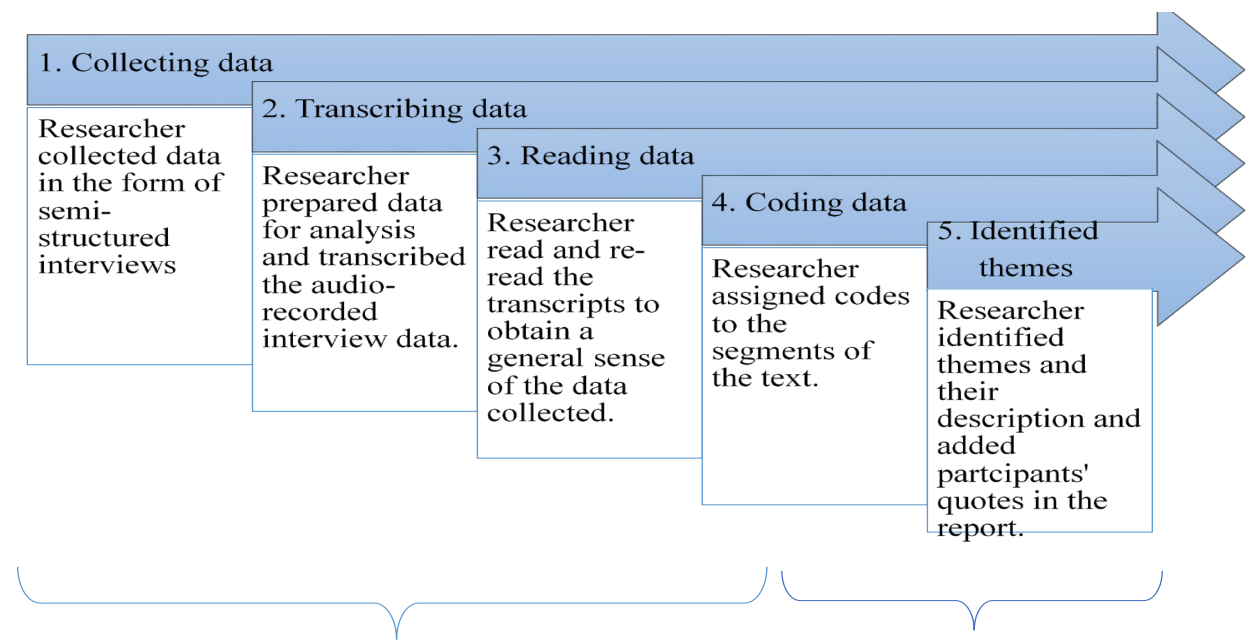

Occured simultaneously

Occured simultaneously

Figure 1: The qualitative process of data analysis (adapted from Creswell 2012)

\section{Data analysis}

Item by item content analysis was made where, for each interview item, recurrent words reflective of respondents' views were flagged and analysed. Figure 1 shows the data analysis procedure that was followed. 


\section{Ethical Considerations}

The study complied with ethical protocols governing the conduct of research and protection of the rights of participants in relation to, among other things, privacy (confidentiality and anonymity), informed consent (voluntary participation), and how the data was interpreted honesty (Leedy and Ormrod 2010). The researcher sought institutional consent to conduct the study, as well as written informed consent from the participants. Their right to withdraw their participation was guaranteed, as was their right to privacy (avoiding identifying information in the texts, the audio-recording, transcriptions, and reporting of findings). The data obtained was only used for the purpose of the study. Permission to audio-record interviews to ensure accurate capture of respondents' views was granted by the participants.

\section{VALIDITY}

Member checking of interview data for accuracy of its interpretation was done via e-mail to participants. The participant only got the data that pertained to their interview and the researcher's interpretation of it. In line with Lichtman's (2013) caution against misinterpretation, over-interpretation or fraudulent analysis of data; a reading and re-reading of data was made.

\section{PRESENTATION AND ANALYSIS OF FINDINGS}

Although the question, "what is decolonisation?" was the focal point of the study, conceptions academics held could be inferred from their responses to related questions like; whether decolonisation was necessary, what needed to be decolonised, what decolonisation was not, and how curriculum in their specialisations would look like when it is decolonised. In the analysis of responses to each of the six items, care was therefore, taken to read the responses in the light of the respondents' conceptualisation of decolonisation.

\section{Should universities decolonise?}

As a point of departure, it was important to ascertain whether respondents were for the decolonisation of HE. In response to whether universities should decolonise, respondents were almost unanimous on the need to decolonise the university, with some expressing the need more strongly (A2, C1, A6, A5 featuring words definitely, certainly, and of course) than others (B2, A7, A1, C2). For some (C3, B1, A4), their answer in the affirmative depended on how the term was defined. C3 particularly noted that the need to decolonise was conditional upon it opening up spaces for other knowledges to be recognised. Only A3 argued against decolonisation from 
the position that knowledge was already fixed in his disciplines, through facts, laws, and principles which needed not to be disturbed. He cited the fixed nature of $1+1$, of ohms' law, of gravity and posited that the few prospects for decolonisation was "... if you teach Consumer Sciences where you can teach them about our traditional foods; or in English where you teach them our dialects". A3 believed in selective application of decolonisation in relation to the nature of the discipline's content knowledge. For him decolonisation had curriculum content as its target. Reference to traditional foods and dialects was an implicit equation of decolonisation with localisation. The response implied that a replacement of a Western or non-traditional dish with a traditional dish in a Consumer Science class amounts to decolonisation of a curriculum even if the teaching method and the cooking methods are the same. For all the other participants, the fact that they had an opinion on the need or not for decolonising the university meant they all had some conception of the term, and so determining their justification for decolonisation was important.

\section{Why decolonise?}

All responded to the question on the rationale for decolonisation except for C3. Central in most responses was the issue of dissatisfaction with the current status quo, and the need for redress. The word Eurocentric featured prominently in the description of the status quo (A2, C2, A5, $\mathrm{B} 1, \mathrm{~A} 4)$, as well as the word Western $(\mathrm{A} 1, \mathrm{~A} 8)$ in describing the current university configuration and education system. This was juxtaposed against the fact that students hailed from "backgrounds that are not typically Eurocentric" (A2), an observation echoed by A5 and B2. The disjuncture occasioned by a Eurocentric education offered to a non-Eurocentric student body, is articulated by the buzz phrase of "not speak to" which was used by C2, B2, B1, A5, A4 to describe the articulation between the university curriculum and the intended target of the curriculum, the students, and the community for B1. The misalignment is seen as being occasioned by: the erroneous assumption of a universal "one-size fits all" curriculum (A6), the university's desire to accommodate the "world of work" rather than the ever evolving student profiles, the need to "benchmark" with other universities which the respondent saw as an attempt at "pleasing the master" $(\mathrm{C} 2)$, the mindset "that everything that is coming from Europe or the Western world is the only truth" (A5); or that "Western knowledge is set in stone as the absolute truth" (A8); and "training people to be subjects of other people" (A6).

The redress component in the responses had to do with: contextualising or localising the curriculum (C1, A5, A1) to better reflect the students' world (B2, B1, A4); challenging and dismantling the perceived sanctity of Western knowledge (A5, A8); "undoing the colonising practices" (A6), and integrating currently peripheral knowledges into the mainstream 
knowledges (B2, A4, A8) and treating them as "the basis from which we teach the other kinds of knowledges" (A4), thereby redressing the inequalities of education (A2, A6). Within both the discourse of dissatisfaction with the status quo, and the measures for redress; knowledge and truth, as reflected in the subject matter or content, emerged as key terms in the decolonisation agenda.

The rationale for decolonisation given by $\mathrm{C} 4$ as developing "a more rigorous, more multifaceted, more engaging curriculum" was reflective of the need to bolster the academic worth of the curriculum and not necessarily the decolonisation focus. A curriculum could attain to the standards of rigour and engagement without necessarily being decolonised. Equally uninstructive and potentially reflective of little conception of decolonisation was A7's reason for decolonisation being "to listen to our students" who needed to be heard.

The need to contextualise the curriculum by infusing home previously marginalised home grown indigenous knowledges derived from Africa was the major argument advanced, with the terms in italics recurring in the responses. The justification implied a realigning of the university to the context, which by default, is a realignment to the students. What it meant was that, for the majority of the participants, the locus of enunciation of knowledge (i.e., community, indigenous people, Africa, Southern Africa, South Africa) is what rendered it decolonised. It was more the geography of the knowledge which mattered, which was assumed translated to meeting the needs of students inhabiting the geographical space. For A4, decolonisation was simply the replacement of Western theories with African ones, as shown by his advocacy for substituting Bernstein for Nyerere and Shakespeare for Chinua Achebe; translating to a replacement of Europe with Africa, and not about overhauling the core of the knowledge base. In the Nyerere-Shakespeare example, it implied that the principles of literary interpretation were fine, and what needed replacement were texts. Decolonisation then became a surface enterprise, dealing with the observable cosmetic manifestations of knowledge but retaining the underlying core of the knowledge. For me, that amounts to giving a flavour to, than dismantling the status quo. C2's emphatic affirmation to the need for decolonisation in the first item was consistent with his stance that the coloniser's system needed overhaul so that "we do our own things".

A3 was consistent in his denial of the need for decolonisation, seeing decolonisation as potentially excluding students from the world, and rendering them internationally irrelevant. Implicit in his caution was the assumption that decolonisation was teaching content that applied only to the local context, and that decolonised curriculum could not attain international stature.

However, as the overwhelming majority had ascertained the need and rationale for decolonisation, it was important that their views be sought on what they believed should be the 
target of decolonisation.

\section{What aspects of the university should be decolonised?}

A3, who was consistently against the decolonisation of the curriculum, proscribed decolonisation to the university social life in the form of cultural dances and other forms of socialisation. B1 opined that it was "the mind" that needed to be decolonised in whatever possible way. He refused to commit to specific ways through which the decolonisation of the mind could be effected. The rest of the respondents opined that "the curriculum" was either "the must-decolonise component" of the university (A7, C2, A4, A8), or one of the "mustdecolonise aspects" of the university (A1, A2, A5, A6, B2, C1, C3). However, there was no uniformity in the way the curriculum was defined. A7 identified the curriculum and texts and A5 indicated the curriculum and knowledge as meriting decolonisation; suggesting texts and knowledge were not subsumed in the curriculum. The breadth of respondents' definitions of curriculum seemed to influence what they envisioned as the ideal target of the decolonisation project.

Over and above the curriculum, $\mathrm{C} 1$ added research; $\mathrm{A} 2$ noted "the entire vibe of the university"; A6 indicated the classroom environment, which despite its modernised state, retains its traditional essence; A1 identified "the idea of what a university is"; B1 noted "our values"; B2 the environment for example our residences (A1, B2), as the targets of decolonisation. The over-emphasis on the official curriculum as the target for decolonisation was apparent in the respondents' reference to university aspects needing decolonisation as texts, knowledge, discourses, content, curriculum, syllabus, what we teach, among other terms used. There was focus on the content and less focus on the intangible and the totality of the university experience. Whether issues like teaching and learning methodologies, assessment and certification regimes, language of access to the curriculum, and other topical issues in Higher Education (HE) were subsumed in the respondents' definitions of curriculum was not apparent in the interviews, and the present study considered them conspicuously absent in academics' discourses on decolonisation of the university. Ndlovu-Gatsheni's (2013) call for the decolonisation of the African imagination projects the decolonisation agenda as one of restoring agency in the African mind and not just a cosmetic replacement of observable phenomena and configurations.

Having used the term decolonisation several times in response to the first three questions, it was instructive to determine what the respondents considered myths about the concept, enroute to their definition of the term. 


\section{What is decolonisation not?}

The recurring theme in most responses to what decolonisation was not, was that decolonisation did not mean rendering all Western forms of knowing obsolete. Respondents cautioned against: overhauling the system in the name of decolonisation; "destroying everything that we have been doing so far" (C2), "taking everything up-side down and making the system ineffective and inapplicable to the world of work" (A2), "throwing out the baby with the bath water" (A4), among other expressions. The point most respondents made was the need to retain the "good", "functional" aspects that have been inherited from the West. It was interesting to note how some respondents, who had intimated an overhaul of the system, toned down in response to this question and acknowledged some positives in the current status quo which merited retention. Noteworthy was C2's response "Maybe good things we have learnt from the colonisers; why don't we keep doing them," against his earlier observation that the whole system was meant to please the colonial master, and that it was time we did our own things.

There were also cautions against: stigma against, and aggression towards the West as the enemy (B2); politicising decolonisation (A5); misconstruing it as a project of "Africans representing European information" (C3); exclusively "looking at African knowledge" (A4); conflating decolonisation with transformation (B1); thinking decolonisation is novel and unrelated to other initiatives currently underway (C3); "teaching for Africa and not the global village" (B1); thinking "that the curriculum is decolonised as long as you have a textbook written in South Africa using South African examples"(A4); the assumption that institutions established after apartheid were decolonised (A4); and against "just giving something an African flavour" (A1). The responses were emphatic about decolonisation not being an exclusive but inclusive knowledge project, and about it not being a superficial cosmetic project.

Accounting for what decolonisation was not, set the stage for the key question of the study of what decolonisation was.

\section{What then is decolonisation?}

Ironically, of all the items, respondents exhibited the greatest hesitation in responding to what decolonisation is. It was defined as: legitimising, valuing, accepting, exploring, affirming all knowledges and striving for parity and equality among knowledges (B2, A4, A8); opening up (university) access (in the multiple meanings of the word, I assume) to the greatest number of students (A2); "an African view of things" (C1); reimagining knowledge, curriculum, and problem solving (A7, A1), inclusion of "things done by Africans in the curriculum" (C2), "contextualising our universities so that our students can relate to what they are learning" (A5), reforming the structural and intellectual aspects of the university to ensure access and 
relevance (C3), ensuring the colonial legacies and colonising practices are changed in the current dispensation (B1, A6). A6 exemplified the extant colonising practices inherent in the education system where the African languages teaching is a translation of that of English. Decolonisation was seen as inclusive and accommodative to the extent that "there is a place for all at the rendezvous of victory" (A6) and that there was merit in even bringing some of the contested knoweldges into the curriculum, if only to challenge them (C1). Decolonisation was seen as an adding on to, rather than a disruption of, extant knowledges by some (B2, A4, A8) and by others (A6, C3); as an adding on to, disruption of some parts, and retention of other parts of, extant knowledges The word Africa or African again featured prominently suggesting a conflation of decolonisation with africanisation. A3's version of decolonisation was "not doing anything Europe has taught us and doing things the African way". The extreme nature of his conception of decolonisation accounted for his aversion to the decolonisation project.

Now that the respondents had noted what decolonisation was and was not, and the target and rationale of decolonisation, it was imperative that they visualise a decolonised version of the curriculum in their different specialisation areas.

\section{If you were asked to decolonise your module, what would go, what would remain, and what would come in?}

In response to the above question, reference was made to respondents' areas of specialisations. For A2, decolonisation would be manifest in the inclusion of literary texts from a more diverse Afrikaans speaking audience to disrupt the myth of a standard Afrikaans spoken and written by Afrikaans white people, and to introduce dialectical variations, according them equal status with the currently dominant variety. A7, who also taught Afrikaans, challenged the relevance of teaching the origin of Dutch epistemology and advocated infusing the translation of texts into other languages and the analysis of "other languages' poetry which is translated to Afrikaans". For her, decolonisation was about ridding from modules, content which lacked utilitarian value and direct relevance for students.

$\mathrm{C} 1$ opined that his Education modules were already sufficiently decolonised by virtue of their content exploring issues of equality, equity, and non-discrimination. For him, content advocating such ideals in a module amounted to the module being decolonised. The only module he proposed decolonising was one which was not critical enough to conscientise students, owing to it being authored by White South Africans. The remark subtly reduced decolonisation to a racial agenda of the blacks in which Whites were not African enough to participate, and where white authored texts were suspect. It is reminiscent of some narrow conceptions of transformation which equate it to racial essentialism manifest in the replacement 
of the White with Black, be it in literary texts, theories etc. A3 was adamant about the poor prospects of a decolonised curriculum when he indicated that in the Technical Drawing field, getting rid of all that is Western (which is how he defined decolonisation) would mean not having any texts as none emanated from Africa. For him, nothing needed to change. C2 noted that he would change the approach to mathematics where he would teach "factorisation or equations" using students' everyday practices. This respondent, who had advised ridding the university of the coloniser's curriculum, only recommended change in the delivery of content, not in the content or knowledge itself, or even its packaging.

For B2, highlighting the varieties of English as equally legitimate in her new modules would amount to decolonisation. A5 was for retaining theories of language learning, which she saw as speaking to all languages, but ridding the system of textbooks with foreign pictures, content and examples. Kasturi $(2019,62)$ reports on Garuba's study where "[s]tudents also questioned the basis of university texts, which favour a Western and Northern rationality, replete with examples that privilege those with the cultural capital to succeed at the university". Both lecturers of English could hardly say how they could decolonise the coloniser's language which carried with it the coloniser's culture. Decolonising for them, was acknowledging the varieties of English and contextualising English texts. Without specifying, A4 saw the decolonisation of academic literacies as loosening some of the strict prescriptions characterising acceptable academic writing. This could be construed to imply decolonisation was about relaxing standards to accommodate student diversity; a taking of the "standards" to the students" levels not the students to the "standards".

For C3, the current History curriculum was the story of the hunter and not the hunted, and decolonising it would require infusing the sciences that affirm other knowledges like oral tradition and archaeology, and not just relying on the written word. Decolonisation in that regard, had to do with broadening ways of determining what knowledge was worthwhile.

B1 was okay with the current Technology module because of its utilitarian value as students were taught to produce what humans used. Adding indigenous technologies would complete the module. Utility of a module and infusion of indigenous knowledge equalled a decolonised module for him.

To decolonise curriculum, A6 noted that he would add the way of life of amaXhosa to make it IsiXhosa than just teaching the language divorced from the people of the language which reduced it to Xhosa. "We are teaching Xhosa, which is an English version of IsiXhosa." He bemoaned how the teaching of IsiXhosa was patterned after, and judged on, English terms. He gave an example of there not being a Xhosa way of writing a poem but the romantics' way of writing poetry. 
"When a student leaves, they leave knowing figures of speech, parts of speech, how to construct a sentence, syntax. They leave knowing how words are constructed-morphology and all that stuff, but they don't know the people, the way of life, the culture of amaXhosa. I think if it were to change, it would more embrace the people of the culture and the culture of the people."

For A8 just adding indigenous knowledges where he could in his field would decolonise it. According to Le Grange $(2018,10)$, “[i]ndigenising concerns the inclusion of indigenous ways of knowing and being in social and education processes". For A1, decolonisation would be in the form of linking theory with practicals, and reducing the disproportionate emphasis on examinations and theory in her Natural Science module. Again, the infusion of indigenous knowledges featured. It was questionable whether bridging the divide between theory and practice was a decolonisation issue or just good practice. The same could be asked for reducing the weight of examinations and theory.

In some cases, there was a disjuncture between what the respondents said about decolonisation and how they envisaged decolonising their modules. Some of the proposed measures were just to improve the modules but not necessarily to decolonise as defined by the participants themselves. A7, A4, and $\mathrm{C} 1, \mathrm{~A} 1$ responses are instructive in that regard. The utilitarian value of the knowledge was misconstrued to imply its decolonised state in C1, A7, and $\mathrm{B} 1$ responses. Some proposed changes related to replacing texts, which amounted to tokenism and to giving an indigenous flavour to the current curriculum. In the ensuing discussion of these findings, I sought to answer three questions, namely:

- Of the four decolonisation perspectives derived from literature, which perspectives found expression in the participants' responses?

- Were individual respondents consistent in their conception of decolonisation in their response to the six main interview questions?

- Which related terms (to decolonisation) were apparently made reference to by the respondents in their responses?

\section{DISCUSSION}

The decolonisation perspectives that found resonance with the respondents' ideas, were decolonisation as decentring and decolonisation as recentring. In response to the first two interview items (whether to decolonise and rationale for decolonisation), responses seemed to largely favour a recentring perspective where respondents either wanted an overhaul of the status quo or a seeing of knowledge from the indigeneous, local or African point of view. In the 
responses to items 3 to 6 (what to decolonise, what decolonisation was not, what it was, and how it would manifest in curricula), the stance of decolonisation as an overhauling of things and the West as the enemy, to use one participants' phrase, was generally dropped. Decolonisation became all about respecting the legitimacy of all knowledges by bringing in the marginalised ones into the mainstream curriculum. Responses then took a "decolonisation as decentring" perspective. There was advocacy for knowledge parity, and in some cases, veiled acceptance of the superiority of extant knowledges and the need to complement and bolster them using the currently excluded knowledges. In the last interview question, respondents identified, not as much that needed to go, as needed to come in. There was not much advocacy for the other two decolonisation perspectives. Knowledge was still boxed as indigenous, African, Afrocentric, Western, among other designations. What Samuel (2017) sees as the emic and home grown, culture specific; and the etic, generic, universalist, knowledge remained recognisably different and discriminable.

The shifting nature of conceptions as interview questions changed (alluded to in the previous paragraph) was manifest in the responses given. For want of space, responses of three participants (A2, A3, C2) are instructive for the consistence or lack of consistence in the responses that individuals gave. In item 2, A2 noted that the Eurocentric education system was misaligned to students' needs; for item 3 , he called for a change in "the entire vibe of the university"; for item 4, he cautioned against "taking everything up-side down"; and at a practical level (item 6), he proposed adding texts from different dialect groups, which is not like the overhaul suggested in the initial responses. C2's response to item 2 showed that he was all about overhauling the system to rid it of the coloniser's curriculum and language, and not to seek "to please the master". To the fourth question, he advised retaining good things learnt from the colonisers. For the decolonisation of the modules, the participant proposed, not an alteration of the knowledge base, but the use of daily practices like indigenous games in teaching the extant knowledge. Similar to A2, C2 had a gradual toning down in his view of decolonisation, as the interview progressed from question 2 to 6 . Of all the participants, A3 consistently expressed both the undesirability and impossibility of decolonising the formal or official curriculum; arguing only for the relevance of decolonisation within the social life of the academy.

What makes the definition of decolonisation challenging is the several terms that relate to, and are conflated with, it. In the responses, decolonisation was associated more with Africanisation / Africanism and indigenisation of curriculum than any other terms, in a bid to de-Europeanise knowledge. The local or indigenous was defined in African more than South African terms. Within the raging decolonisation debate, Africanisation features prominently as a key concept but there seems not to be sufficient theorisation of Africa and African. Chikoko 
(2016) asks pertinent questions about what qualifies scholarship as African, how that African scholarship can be engaged with, the source of diverse interpretations of African scholarship, and whether we can and should, converge in our understanding of African Scholarship. Samuel adds whether it is "... scholarship in, for, from, and about Africa" (Samuel 2017, 91). To the list, I would add, who qualifies as an African? These concerns were not addressed in the participants' responses though. Samuel $(2017,91)$ proposes sufficient engagement with "... the notion that the African continent is patterned with a mosaic of differing intersecting cultural systems ...”. Le Grange $(2018,10)$ distinguishes between Africanisation and Africanism, with the latter transcending the demographic representation of a people to "making African culture the centre of Africa's development". In that respect, Africanism featured more prominently in academics' conceptions.

\section{CONCLUSION}

The foregoing presentation and analysis of the findings support two major conclusions. The first is the observation that individual academics do not necessarily hold single and consistent views on what constitutes decolonisation or even curriculum for that matter. The conceptions shift depending on the questions they are answering to, in some instances to the point of contradiction; where there is a theoretical view of the concept markedly diverse from the applied view of the concept. The former is more radical than the latter. A second conclusion supported by the study findings is that academics' views both diverged and converged on different aspects of the term's conceptualisation and application. Divergence was manifest in how radical and far reaching the application of decolonisation needed to go. C3 and A6 took on a more radical stance calling for the acceptance of hitherto marginalised sciences in determining the content of History, and delinking the teaching of IsiXhosa from the principles governing the teaching of English, respectively. terms of the radical. Superficial and conservative application of decolonisation were manifest in the proposal to change textbooks, add local examples to the curriculum and append some indigenous knowledges into the curriculum. There was, lack of consistence, not only on the depth of the decolonisation project, but on its focus and breadth as well, with some seeing it as something to apply to the mind, to the curriculum (in the different curriculum definitions), to the whole university system and the idea of it, among others. Convergence was more on the locus of enunciation, where the words Africa and African were ubiquitous. Africa featured more as a geographical rather than an intellectual space, where the importation of anything emanating from the continent equalled decolonisation. In that regard, a book by a South African writer would be assumed to be fine and one by an international writer suspect, never mind the issues raised. Conceptualisations of 
decolonisation were largely at the meta-theoretical level, where underlying assumptions were made regarding what merits to be taught; and at the applied knowledge level where the social reality of students needed to inform the curriculum. There was not much discourse at the theoretical level where theories and concepts are generated; or the pedagogical level where teaching methods responsive to the students are selected; or even at the empirical level.

\section{RECOMMENDATIONS}

On the basis of the findings and conclusions drawn, the study proffers three recommendations. First, that the notion of Africa and African within the decolonisation debate be problematised and troubled. Second, that any attempts to "decolonise" either the university curriculum or the entire university be premised on the understanding of the pluralistic nature of the concept. Third, that there be a broader discussion on which should be subordinate to the others; issues of equity or equality of representation of contesting knowledge on the one hand, or questions of relevance and epistemological access to, and success of, the current profile of university students.

\section{REFERENCES}

Chikoko, V. 2016. "Issues in Africanising higher education curricula." In Africanising the curriculum: Indigenous perspectives and theories, ed. V. Msila and M. T. Gumbo, 71-82. Stellenbosch, South Africa: SUNMeDIA.

Chilisa, B., T. E. Major, M. Gaotlhobogwe and H. Mokgolodi. 2016. "Decolonizing and indigenizing evaluation practice in Africa: Towards African relational evaluation approaches." Canadian Journal of Program Evaluation Special issue 30(3): 313-328.

Chiumbu, S. 2017. "Why decolonise research methods? Some initial thoughts." Presentation: HSRC Seminar series, 2 May. http://ecommons.hsrc.ac.za/handle/20.500.11910/10905 (Accessed 1 February 2018).

Cohen, L., L. Manion, and K. Morrison. 2011. Research Methods in Education. $7^{\text {th }}$ Edition. New York: Routledge.

Creswell, J. W. 2012. Educational research Planning, conducting, and evaluating quantitative and qualitative research. $4^{\text {th }}$ Edition. Boston, MA Pearson.

Emeagwali, G. and G. J. Sefa Dei. (Ed.). 2014. African Indigenous Knowledge and the Disciplines. Rotterdam / Boston / Taipei: Sense Publishers.

Kasturi, B. 2019. "Decolonial Turns, Postcolonial Shifts, and Cultural Connections: Are We There Yet?" English Academy Review 36(1): 58-68.

Leedy, P. D. and J. E. Ormrod. 2010. Practical Research: Planning and Design. $9^{\text {th }}$ Edition. Pearson Educational International, Boston.

Le Grange, L. 2014. "Currere's active force and the Africanisation of the university curriculum." South African Journal of Higher Education 28(4): 1283-1294.

Le Grange, L. 2016. "Decolonizing the university curriculum." South African Journal of Higher Education 30(2): 1-12.

Le Grange, L. 2018. "Decolonising, Africanising, indigenising, and internationalising curriculum studies: Opportunities to (re)imagine the field." Journal of Education 74: 4-18. 
Leibowitz, B. 2017. "Cognitive justice and the higher education curriculum." Journal of Education 68: 93-111.

Lichtman, M. 2013. Qualitative research in education. $3^{\text {rd }}$ Edition. SAGE Publications. Inc.: Thousand Oaks.

Mbembe, A. 2015. "Decolonizing knowledge and the question of the archive." http://wiser.wits.ac.za/system/files/Achille\%20Mbembe\%20-20Decolonizing\%20Knowledge\% 20and\%20the\%20Question\%20of\%20the\%20Archive.pdf. (Accessed 29 May 2018).

Motta, S. C. 2013, “Teaching global and social justice as transgressive spaces of possibility." Antipode 45(1): 80-100.

Ndlovu-Gatsheni, S. J. 2013. "Why Decoloniality in the 21st Century? The Thinker for Thought Leaders." Journal for Progressive Thought 48(10): 10-15.

Olivier, B. 2019. "Decolonisation, Identity, Neo-Colonialism and Power." Phronimon 20: 1-18.

Samuel, M. A. 2017. Book Review of "Africanising the Curriculum: Indigenous Perspectives and Theories" by Vuyisile Msila and Mishack T. Gumbo (Eds.). Educational Research for Social Change (ERSC) 6(1): 87-92.

Santos, B. S. 2009. "A Non-Occidentalist West? Learned Ignorance and Ecology of Knowledge." Theory Culture \& Society 26(7-8): 103-125. 